introduced a large amount of thickening was felt in the region of the pylorns, extending both towards the stomach and the duodenum. The stomach was somewhat dilated The operation of retrocolic gastro-jejunostomy was performed, the portion of jejunum selected being about seven or eight inches from the commencement of that part of the intestine. The stomach and jejunum were joined by a double row of continuous stitches, the mucous membrane being united by catgut and the peritoneal and muscular coats by silk (see diagram $(a)$ ). In addition to this, a jejuno-jejunostomy $(b)$ was performed at the same time so as to avoid any chance of a vicious circle being set up, a plan which I now generally adopt. The arrows indicate the direction of the natural flow of intestinal contents and the purpose which is served by the double opening, (a) serving for the passage of stomach contents directly into the jejunum and (b) allowing the bile and pancreatic fluid to pass directly down the intestine without first mounting into the stomach.

Mayo Robson and Moynihan ${ }^{1}$ make the suggestion that oral sepsis is responsible for many gastric ulcers, a view with which I quite concur, but I have never before come across a case in which the clinical evidence of this view was presented in so striking a fashion. It seems to me, therefore, worthy of record. Anything which emphasises the dangers of oral sepsis deserves to be recorded.

Harley-street, $W$.

\section{THE RÔLE OF AN EXCESSIVE MEAT DIET IN THE INDUCTION OF GOUT.}

By D. CHALMERS WATSON, M.D. Edin., F.R.O.P. Edin., LATE PHYSICIAN, MARSHALL-STREET DISPENSARY, EDINBUTGGH.

IN 1904 I submitted evidence in favour of the view that there is an infective element in gout. This evidence was obtained from the examination of the tissues from a case of acute gont in a fowl ${ }^{2}$ and from the histological examination of the tissues in chronic gout in man. ${ }^{3}$ It may be some time before conclusive evidence of the existence of an infective element is available. If we provisionally accept this view the question naturally presents itself as to how far its adoption is in harmony with a well-established fact of the disease-viz., the importance of diet (solid and liquid). It appears to me that a belief in the infective nature of gout in no way minimises the importance of a study of diet and for this reason: if there is an infective element in the disease the main source of infection is the digestive tract and there is good reason to believe that the activity of the bacteria in the intestinal contents must depend largely on the character of the foodstuffs.

In view of the generally admitted fact that an excess of meat diet is prejudicial to most gouty subjects I have sought to determine by observations on animals whether an excessive meat diet exerted a specific action on any of the ductless glands. My results have shown that a diet of raw meat and water (Salisbury diet) exercises a very marked effect on the thyroid glandular system. The results obtained from investigation in poultry were communicated to the Physiological Society in March, 1904, and in December the results of a similar investigation on rats were communicated to the same societr. The present paper is a résumé of the more salient features of these investigations from the clinical standpoint.

The effect of an exclusire ran meat and water diet on the thyroid and parathyroid glands in poultry.-As a result of feeding three healthy fowls on an exclusive raw meat and water diet for periods ranging from 13 to 16 months, a very striking hypertrophy of the thyroid and parathyroid glands was induced in all the animals. The parathyroid glands, instead of being microscopic structures, appeared as large glands, considerably larger than a pea; the thyroid glands were much enlarged and weighed from eight to ten times or more the weight of the normal gland. Histologically the

1 Diseases of the Stomach and their Surgical Treatment. 1904 Second edition, p. 165 .

2 Observations on the Pathogenesis of Gout, Brit. Med. Jour, Jan. 9th, 1904

3 Further Facts in Favour of an Infective Element in Gout, Brit. Med. Jour., July 16th, 1904. parathyroid glands showed the normal appearance of parathyroid tissues; the thyroid glands presented the appearances characteristic of simple parenchymatous goitre in the human subject-viz. (see Figs. 1 and 2), great enlargement

FIG. 1.

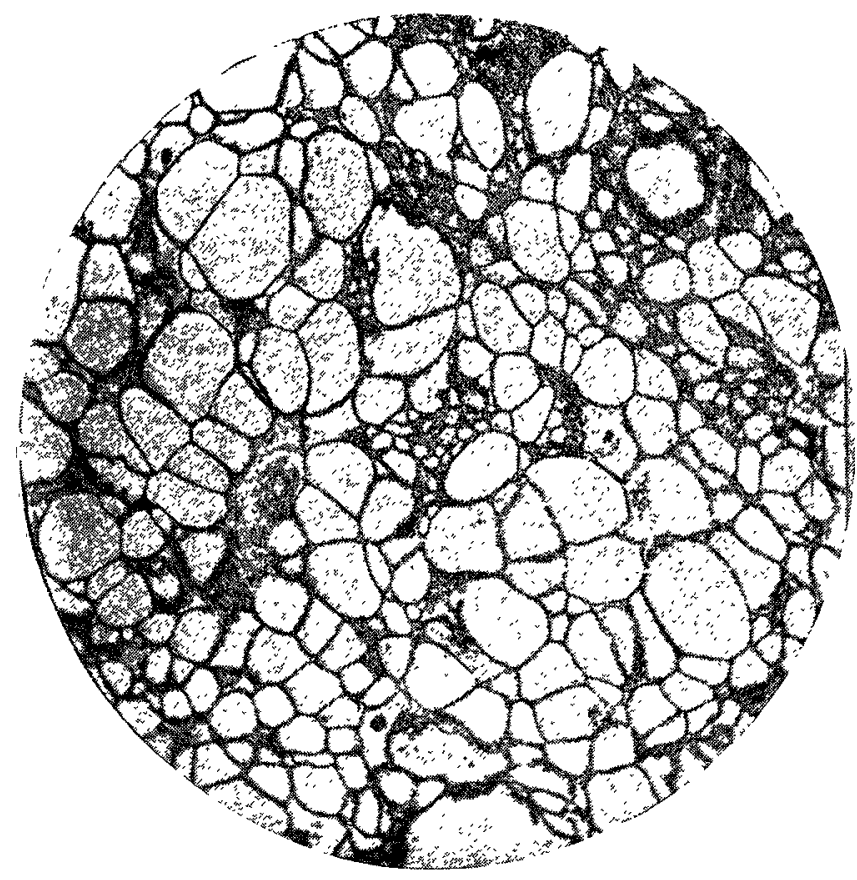

Thyroid gland of fowl ferl on ordinary food. $(\times 50$.$) Observe$ (1) the size of the vesicles; (2) the thickness of the walls of (1) the size of the vesicles; (2) the thickness of the walls of the vesicles; tissue. Cf. Fig.

FIG. 2.

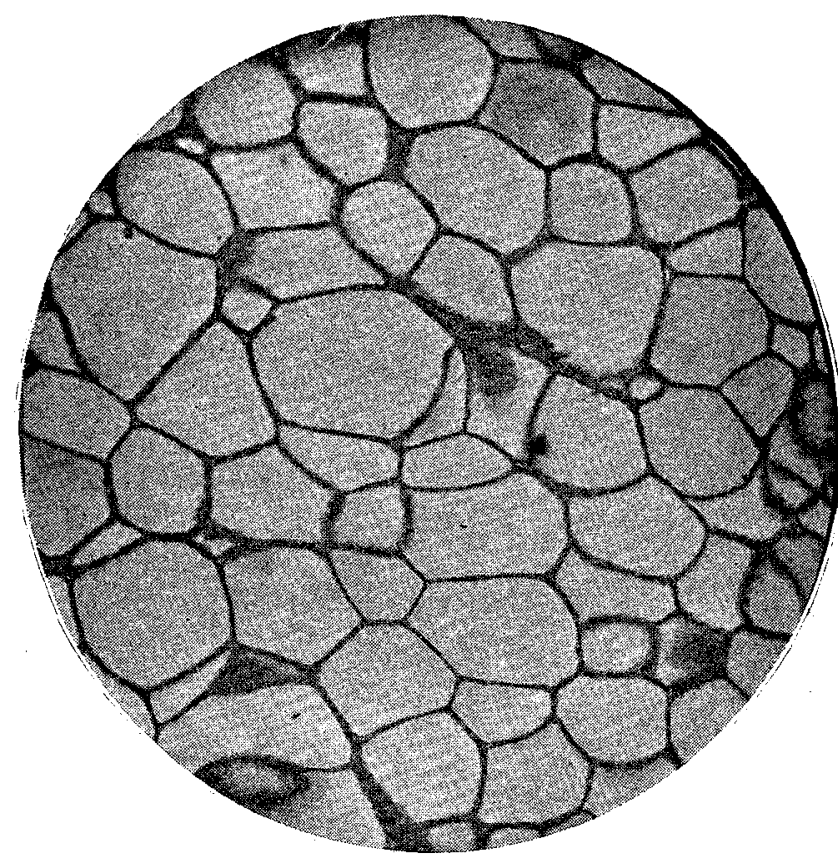

Thyroid gland of fowl fed on raw meat and water. ( $x$ 50.) Observe (1) the increase in size of the resieles; (2) the increased thickness of wall of the resicles; (3) the diminution in amount of intervesicular glandular tissue. of. Fig. 1.

of spaces which were distended with colloid material, enlargement of the wall of the vesicles, and in some areas proliferation and shedding of the epithelial cells, with hæmorrhage into the vesicles. So far as I am aware, this is the first time that there has been induced experimentally in animals an enlargement of the thyroid gland similar to that seen in simple parenchymatous goitre in the human subject.

The effect of an exclusine ran meat and water diet on the thyroid and parathyroid glands in rats.-As the result of an investigation on 12 animals which were fed on an exclusive raw meat and water diet for periods ranging from six weeks to four and a half months it was found that definite changes were induced in the thyroid gland in the great majority of cases (ten out of 12). The nature of the change was, however, quite different from that observed in the case of the poultry. The distinctive features were observed on histological examination (see Figs. 3 and 4 ), which showed $(a)$ 
diminution in colloid material; (b) proliferation of the epithelial cells and also of the connective tissue; (c) evidence of rapid degeneration of the colloid into a mucinoid material ; and (d) congestion of blood-vessels. Professor W. S. Greenfield kindly examined some of these specimens and pointed out to me that in the more marked cases

FIG. 3.

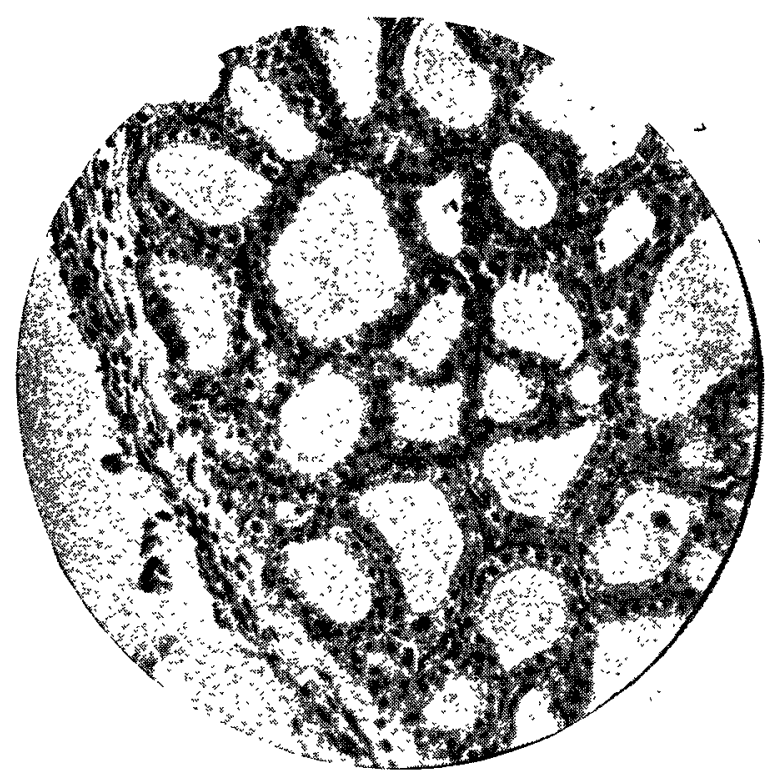

Thyroid gland of rat fed on bread and milk. $(\times 200$.$) Observe$ (1) the size of vesicles and regularity of outline; (2) the colloid material in the vesicles. Cf́. Fig. 4.

FIG. 4.

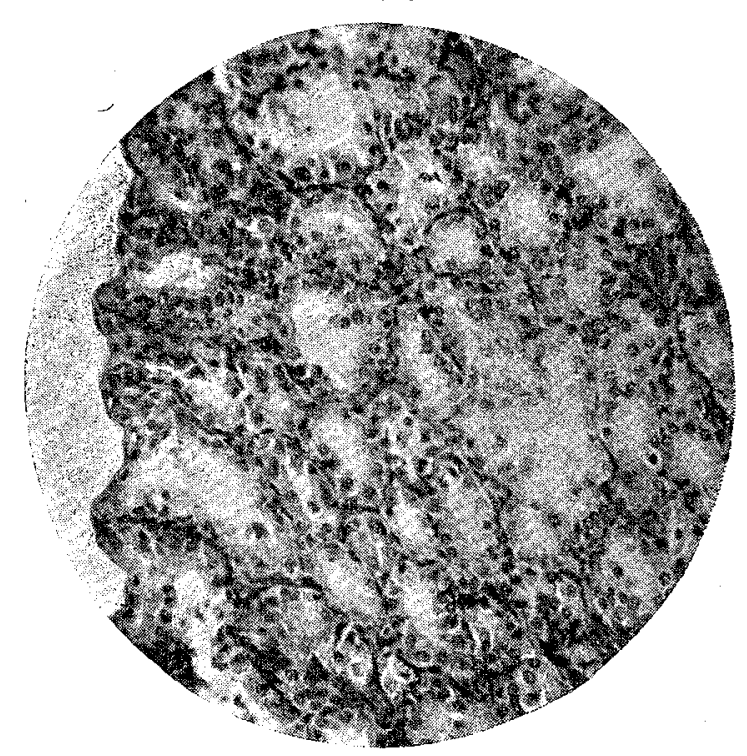

Thyroir gland of rat fed on raw meat and water. $(\times 200$. Observe (1) catarrhal changes in the epithelium; (2) diminution of the colloid material.

the appearances bore a striking resemblance to those seen in exophthalmic goitre in the human subject. In the case of the one adult meat-fed rat, which succumbed after three weeks of the diet, the appearances of the gland were those of an advanced atrophic catarrh with complete absence of colloid. In the great majority of cases the parathyroid glands were normal. So far as I am aware, this is also the first occasion on which it has been directly shown that a particular diet induces distinct histological changes in the thyroid gland of an omnivorous animal (rat), and, further, that these changes are of a nature similar to those seen in the gland in cases of exophthalmic goitre in the buman subject. It should be stated that the animals showed no other signs or symptoms of this disease.

Remarks.-The results obtained from the two investigations agree in showing that a diet of meat and water profoundly influences the thyroid gland. In poultry the diet induced a striking hypertrophy of the gland with great increase of colloid material which appeared for the most part normal. In the case of rats the striking change was the alteration in the character of the secretion with catarrh of the epithelial lining of the vesicles, the general appearance of the gland indicating exhaustion of its functions. Further investigations are necessary before the difference in the results obtained in the two classes of animal can be explained. In the meantime it appears to me that these new facts have some practical interest and importance. There are figures in the Blue-book which conclusively prove that there has been a great increase in the consumption of meat in this country in the past 30 years. Evidence is also accumulating to show that thyroid medication is of value in a number of diseased conditions which have no known relationship to the thyroid gland-e.g., skin diseases, mental affections, eclampsia, and other disorders. May not the new facts recorded in the present paper explain the value of thyroid medication in those cases? It is, I believe, possible that as a result of the excessive use of meat there has been established in many subjects an alteration in the character of the thyroid secretion, which defect is remedied in the cases in question by the administration of thyroid gland. The adoption of this view has led me in the past year to try the effect of the administration of small doses of thyroid extract in two inveterate cases of chronic gout which had not been amenable to dietetic measures aided by skilled balneological methods. In both cases the symptoms were relieved to a striking degree, this relief having been so far of a fairly permanent nature.

Edinburgh.

\section{CARBONIC ACID AS A FACTOR IN THE GENESIS OF THE GOUTY STATE.}

BY DONALD F. SHEARER, M.B. Oxon., F.R.C.S. ENG.

THE origin of the gouty state, in which it is usual to group together clinically gout, arterio-sclerosis, and chronic interstitial nephritis, is commonly attributed to the over-production or the retention of uric acid or its salts within the body ; and a bewildering wealth of chemical experiment, of pathological record, of physiological research, of clinical observation, and of polemical argument awaits him who seeks for further enlightenment. So overwhelming is the mass of literature on the subject that one is justified in putting it all aside in order to consider the question de novo and in avoiding the narrow purview of the test-tube or the microscope in order to seek a solution in a less restricted field of vision. We have learnt empirically that these pathological conditions are wont to follow long-continued excesses in diet and also upon deficient muscular activity and we also know that lead poisoning has a definite etiological relationship to them. On the first two we have built our prophylactic and our curative treatments and from them it is possible to trace the genesis of the diathesis. It is interesting to note that notwithstanding all our investigations the modern treatment follows exactly the lines laid down in the days when uric acid was unheard of or had not been causally related to gout. This fact, moreover, which can be verified by a reference to Sir T. Watson's lectures, indicating as it does that uric acid has led us into a blind alley barring further progress, is an additional reason for a wider review.

Now when we have to deal with a common phenomenon following upon diverse antecedents so various as undue indulgence in alcoholic drinks, excessive consumption of nitrogenous food, excess of carbohydrate diet, and insufficient exercise, when we find a mitigation of the symptoms succeeding to an alteration of each separate antecedent as well as of all combined, we may rightly seek for a causal factor common to all the antecedents rather than make the assumption that the cause is other than the known antecedents. A reference to any text-book of physiology tells us that the one factor common to all the antecedents of gout is the tendency to the production of an excess of carbonic acid in the blood. The cardinal feature of muscular exertion is the large increase in the output of carbonic acid without affecting the nitrogenous excreta. Alcohol and carbohydrates can only produce as the end products of their combustion water and carbonic acid. Nitrogenous diet increases metabolism not only of proteid but of carbohydrate and hydrocarbons and thus leads to an increased amount of carbonic acid. And just as the action of the antecedents tends towards an excessive manufacture 